\title{
Gestão e democracia em uma escola pública
}

\author{
Management and democracy in a public school \\ Gestión y democracia en una escuela pública
}

JEFFERSON MARÇAL DA ROCHA LÚCIO JORGE HAMMES

Resumo: Gestão escolar e democracia são os temas instigadores deste trabalho, que tem por objetivo analisar o processo de gestão de uma escola pública do Rio Grande do Sul, Brasil. Partindo-se dos dados coletados nos órgãos de gestão da escola fez-se uma abordagem qualitativa, na perspectiva metodológica da análise de conteúdo. Os resultados apontaram que a escola possui formalmente os órgãos deliberativos previstos na legislação brasileira. Contudo há escassa participação da comunidade escolar, destacando-se a ausência de um efetivo Grêmio Estudantil e a ausência de registro do Círculo de Pais e Mestres.

Palavras-chave: Educação; Gestão; Escola; Democracia.

Abstract: School management and democracy are the themes instigators of this work, which aims to analyze the process of management of a public school in the state of Rio Grande do Sul, Brazil. Based on the data collected in the management organizations of the school made a qualitative approach, in the methodological perspective of content analysis. The results showed that the school has formally the deliberative organizations provided in the Brazilian law. However, there is little participation of the school community, highlighting the absence of an effective Student Council and the lack of registration of the Circle of Parents and Masters.

Keywords: education; management; school; democracy

Resumen: Gestión de las escuelas la democracia son los temas instigadores de este trabajo, que tiene como objetivo analizar el proceso de gestión de una escuela pública de Rio Grande do Sul, Brasil. Desde los datos recogidos en los órganos de gestión de la escuela se hizo un abordaje cualitativo, en la perspectiva metodológica de análisis de contenido. Los resultados mostraron que la escuela posee formalmente los órganos deliberativos previstos en la legislación brasileña. Sin embargo, existe poca participación de la comunidad escolar, destacando la falta de un efectivo Gremio Estudiantil y la ausencia de registro del Círculo de Padres y Maestros.

Palabras clave: Educación; Gestión; Escuela; Democracia 


\section{INTRODUÇÃO}

Este artigo tem como objetivo fazer uma análise do processo de gestão de uma escola pública estadual que oferece todas as etapas do ensino básico: o Ensino Fundamental de nove anos e o Ensino Médio de três anos, em três turnos diários, localizada no município de São Gabriel, RS. Recebe educandos filhos de famílias da classe social de trabalhadores, residentes em bairros da periferia da cidade.

Parte-se do pressuposto de que a gestão democrática é um grande desafio para a construção de uma escola em que todos os seus segmentos sejam contemplados, em especial os alunos, que em última análise são o sentido de toda escola. Considera-se também, aqui, que a democracia passou a ser, em tese, o escopo de toda a gestão dos órgãos públicos do país a partir da abertura democrática do Brasil na década de 1980, tendo como marco o movimento "Diretas Já" entre os anos de 1984 e 1985 e a constituinte que culminou com a Carta Magna Nacional de 1988 (PENIN; VIEIRA, 2002; CURY, 2002).

$\mathrm{Na}$ perspectiva da gestão democrática na educação, é imprescindível a participação da família, dos educandos, dos professores, dos funcionários e entidades representativas da comunidade onde as escolas se localizam. Somente com a participação efetiva destes segmentos é que as decisões podem refletir os anseios desta comunidade (FLACH; SAKATA, 2016).

A escola se constitui em um espaço de contradições, diferenças e encontros de grupos sociais com diferentes dinâmicas culturais, religiosas, familiares etc. Esses grupos deveriam articular-se, em aprendizagens coletivas, a partir dos princípios da convivência democrática, promovendo a cultura participativa. Contudo, salienta-se, essa cultura participativa não poderá ser imposta por diretrizes e regulamentos ou, mesmo, por gestores, pois perder-seia o princípio próprio da democracia. Ela deverá ser construída no debate, no conflito de ideais, na argumentação, em uma dinâmica construída pelos próprios membros que compõem a organização escolar (CÓSSIO et al., 2010; ROCHA; VALENTINI, 2012).

Partindo desse contexto, a partir de dados coletados nos documentos escolares, fez-se uma abordagem qualitativa, na perspectiva metodológica da análise de conteúdo, proposta por Minayo (2001); Trivinos (1987) e Bardin (1979). A análise de conteúdo permite, a partir da análise documental, compreender o que foi coletado, confirmar ou não os pressupostos da pesquisa e ampliar a compreensão de contextos. A intenção é compreender para além do que se pode verificar nas aparências do fenômeno, especialmente quando estes se atêm apenas a dados quantitativos. 
Este artigo está dividido em seis partes, incluindo esta introdução. $\mathrm{Na}$ segunda parte, aborda-se, a partir de uma revisão bibliográfica, uma análise sobre o contexto histórico da democracia e da gestão nas escolas brasileiras; na terceira, procura-se esclarecer a metodologia utilizada na investigação; na quarta, a partir de um diagnóstico da escola pesquisada e trazendo para o diálogo os resultados das pesquisas documentais, discutem-se e se analisam os resultados da pesquisa. Na quinta parte destacam-se as considerações finais com uma síntese, à luz da perspectiva teórica utilizada no referencial, os dados encontrados, além de salientarem-se as limitações da pesquisa, e, por último, da sexta parte consta a lista do referencial teórico citado no texto.

\section{GESTÃO E DEMOCRACIA NO CONTEXTO DE UMA ESCOLA PÚBLICA}

Mesmo passados mais de trinta anos da abertura democrática, a reflexão sobre a gestão e democracia em uma perspectiva participativa da coletividade no Brasil é um exercício que precisa ser construído em todas as esferas da vida em sociedade, em especial nas escolas públicas, que deveriam refletir, em suas gestões, os interesses de toda a comunidade escolar. Nesse contexto "Assume papel central, a vontade coletiva, como pressuposto da democracia, tendo na participação dos sujeitos a possibilidade de efetivação" (FLACH; SAKATA, 2016, p. 551). A participação se caracteriza assim como um dos pressupostos essenciais para que se materialize, de fato, uma gestão democrática em qualquer organização pública que prima por esta concepção.

Partindo-se desse contexto, propõe-se, neste tópico, fazer-se uma breve síntese histórica das discussões sobre gestão e democracia, a fim de se subsidiarem as abordagens empíricas a serem analisadas na sequência.

A retomada sobre a democratização da gestão da escola pública no Brasil ocorreu a partir da década de 1980, sob a forte influência do processo de redemocratização do país, após trinta anos de ditadura civil/militar; esse movimento teve uma grande participação da sociedade civil organizada, em busca do resgate dos direitos políticos dos cidadãos brasileiros, que haviam sido usurpados nos tristes anos da ditadura, entre as décadas de 1960 e 1980 (CÓSSIO et. al., 2010). Essa época também marca uma retomada das discussões sobre democracia escolar. 
Dos anos 1980 em diante, os movimentos reivindicatórios dos professores favorecem a discussão sobre o modelo burocrático e hierárquico de reorganização da educação e da escola, propondo a sua superação e democratização. É nesse contexto histórico-político, de transição do centralismo do regime autoritário para a redemocratização, que a gestão é evidenciada na agenda política dos governos (CÓSSIO et. al., 2010, p. 327).

Redemocratizar a gestão pública, frente à opressão imposta pela conjuntura vivida durante os trinta anos da ditadura civil-militar, passou a ser um desafio para todos os gestores dos órgãos públicos. Nesse período, então, as lutas sindicais se aprofundaram na construção de políticas educacionais que atendessem às necessidades e interesses dos movimentos sociais ligados à classe trabalhadora (CURY, 2011; CÓSSIO et al., 2010).

A efervescência política na década de 1980, que teve seu apogeu no movimento Diretas Já, levou à incorporação da expressão "gestão democrática da escola pública" para a Constituição Federal de 1988, em seu inciso VI do artigo 206, posteriormente, referendada pela Lei 9.394/96, de Diretrizes e Bases (LDB) da Educação Nacional - no seu inciso VIII, do artigo $3^{\circ}$ (BRASIL, 2005).

Contudo a primeira dificuldade para efetivar uma gestão democrática na maioria das escolas do país advém do caráter patrimonialista que marca historicamente a cultura nacional; decorre dessa concepção a disposição dos que têm poder econômico e influência social de mandar e exercer influência para exigir obediência dos mais pobres e trabalhadores, como se essa condição fosse natural e inerente à formação republicana do Brasil, formada com bases em uma Monarquia europeia desvinculada dos anseios democráticos, inerentes a formações de Nação republicana (ROCHA; VALENTINI, 2015; SARTORI, 2013; CURY, 2011).

Observa-se que o patrimonialismo já sofreu vários reveses face ao avanço de relações marcadas pela democracia; esse patrimonialismo, porém, não desapareceu, apenas manifesta-se de formas mais sutis e mais aceitas, sendo uma delas a legislação produzida de acordo com interesses patrimonialistas ou a forma como uma mesma lei é interpretada diferentemente, despendendo da condição social do sujeito ou da instituição à qual é aplicada.

O contexto democrático, previsto no art. $1^{\circ}$ da constituição brasileira, implicaria "Uma cidadania ampliada e antagônica a processos de clientelismo ou de quaisquer outras formas de particularismos" (CURY, 2011, p. 16-17).

No campo educacional não poderia ser diferente quanto às normas referentes à gestão escolar. Coube ao Estado à responsabilidade de definir políticas educacionais e as leis que estruturam estas políticas, como a LDB, por exemplo; estabeleceram-se diretrizes amplas que visavam à implementação de uma democracia em todos os níveis da sociedade brasileira. 
O questionamento que se tem muitas vezes é se para implantar os processos democráticos seria necessária uma burocracia normativa, por exemplo. Aqui se defende-se que sim, visto que normas são necessárias em qualquer sociedade, tendo em vista sua organização e funcionamento; deve haver, porém, mecanismos em que as expressões coletivas e as decisões estabelecidas, reflitam de fato a democracia. Com isso, deve-se entender que a autonomia na vida em sociedade é, portanto, sempre relativa, dado que o bem coletivo impõe, muitas vezes, a restrição da autonomia individual. O mesmo ocorre no que diz respeito à autonomia de um coletivo em relação a outro (AZANHA, 2004; CURY, 2011).

A Constituição Federal brasileira no seu artigo 37 dá ao cidadão a prerrogativa para exercer a fiscalização do exercício do poder nas gestões dos órgãos públicos; com isso a gestão democrática como princípio da educação nacional é presença obrigatória em instituições escolares, é a forma que permite que a comunidade escolar fiscalize a execução do projeto pedagógico proposto nas eleições para direções das escolas, por exemplo.

Para o cientista político Norberto Bobbio, a democracia pressupõe que o indivíduo assuma múltiplas funções:

Em termos sintéticos, pode-se dizer que, se hoje se deve falar em um desenvolvimento da democracia, ele consiste não tanto, como erroneamente muitas vezes se diz, na substituição da democracia representativa pela democracia direta (substituição que é de fato, nas grandes organizações, impossível), mas na passagem da democracia na esfera política, isto é, na esfera em que o indivíduo é considerado na multiplicidade de seus status, por exemplo, de pai e de filho, de cônjuge, de empresário e de trabalhador, de professor e de estudante e até de pai, de estudantes... de gestor de serviços públicos e de usuário (BOBBIO, 1987 In: CURY,2011, p. 17).

A autonomia escolar, nas dimensões administrativas, financeiras e pedagógicas está prevista no Artigo 15 da LDB (BRASIL, 2005). No aspecto administrativo, é importante não confundir a descentralização a ser proporcionada/construída/ conquistada com o exercício da autonomia com mera "descentralização" de tarefas. Por outro lado, deve-se também não identificar autonomia da gestão financeira nas escolas públicas, por exemplo, com o abandono/responsabilização das unidades escolares para uma auto sustentação, ainda que parcial, e muito em voga nas políticas dos governos do RS nos últimos anos, o que poderá ocasionar desvios de natureza privatista.

No que concerne à autonomia pedagógica, vale ressaltar que ela deve fazer-se sobre uma base curricular mínima. Tal regulação do Estado faz-se necessária, pois como fenômeno social, a educação do indivíduo não é assunto que toca somente seus interesses individuais, mas os de toda a sociedade. Assim, 
não se pode pretender substituir o Estado, como representante que deve ser de toda a sociedade, em sua obrigação de prover parâmetros e mínimos curriculares, que garantam a atualização histórico-cultural dos cidadãos (PARO, 2000).

A autonomia das escolas, portanto, é mediada por disposições gerais mínimas da sociedade que deverão sobrepor-se a interesses paroquiais, corporativos e individuais.

Contudo, considerando que a razão de ser da educação é a constituição de sujeitos sociais livres e conscientes, a autonomia deve incluir a participação de todos os envolvidos na escola, ou seja, professores, funcionários, gestores e, especialmente, os educandos e suas famílias. Nesse aspecto, é importante não reduzir o educando à mera condição de consumidor ou, ainda, de alguém que assista como mero espectador, pois, em um processo educativo autêntico, ele não é apenas objeto, mas sujeito, razão de ser lato sensu da educação.

Esse contexto de um ideal de gestão escolar foi construído, no Brasil, a partir da década de 1990, que pode ser considerada a década das reformas educativas no país, fruto das grandes transformações econômicas, políticas e sociais pós-abertura democrática. Todos os âmbitos educacionais, etapas e modalidades de ensino passaram por mudanças significativas a partir dessa época. Os primeiros debates giraram em torno do cargo de diretor, os quais eram, em sua maioria, indicados pelas instâncias superiores, quase sempre seguindo interesses políticos partidários, tal situação implicando ingerência nas práticas escolares desconectadas das realidades educativas locais.

Paro (2000) alertava: "Uma sociedade autoritária, com tradição autoritária, com organização autoritária e, não por acaso, articulada com interesses autoritários de uma minoria, orienta-se na direção oposta à da democracia" (p. 89).

Ainda segundo Paro (2000), embora a eleição de diretores possa representar alguns avanços, não tem, por si só, condições de reverter processos tradicionais de gestão. Mesmo assim, o autor considera que o processo de eleição faz emergir e tornar transparentes os conflitos internos, estimulando a relação da direção com as dimensões pedagógicas da gestão.

Embora o processo de eleição possa, entre outros aspectos: favorecer a discussão, fazer emergir e tornar transparentes os conflitos internos, estimular a relação da direção com as dimensões pedagógicas da gestão e diminuir o poder clientelístico de ocupantes de cargo de poder público, há que se entender a escolha livre da direção como apenas uma das alternativas para a produção da gestão democrática da escola e, não necessariamente, como suficiente. A promoção de uma gestão democrática no seu sentido amplo está vinculada à construção de espaços em que ocorra a disposição de todos da comunidade escolar de conversar e debater os problemas cotidianos vividos por ela, do que necessariamente à 
atuação da direção. Tal disposição não resulta apenas de vontades pessoais nem de autorizações de órgãos superiores; depende de um processo de construção coletiva, que é, na sua essência, comunitário e democrático.

Concorda-se com Dourado (1998) que a escolha livre de diretores consiste em apenas uma das alternativas para a produção da gestão democrática na escola, pois a escola é uma instituição construída/criada para atender necessidades da demanda de cidadãos, constituindo-se como um dos mais importantes espaços sociais dentro de um contexto democrático, onde a participação coletiva é mais do que uma necessidade (ROCHA; VALENTINI, 2015).

Para Sartori (2013) "a prática democrática transcende a ação do discurso, constituindo um processo em que seus agentes são seus próprios protagonistas" (p. 67),

Não se pode limitar a análise de processos democráticos, meramente a constituições formais de 'fóruns' de participação, pois estes devem se efetivados na prática cultural coletiva constituída historicamente na comunidade; conforme Norberto Bobbio (2004), quando se quer saber se houve desenvolvimento da democracia em um país, não se pode limitar à quantidade dos que agora possuem o direito de participar das decisões, mas sim, observar, efetivamente, os espaços em que o exercício desse direto está institucionalizado.

Nessa perspectiva, é necessário resgatar o histórico de construção coletiva de cada escola, encontrar seus potenciais de participação já constituídos e, também, refletir sobre os fóruns constituídos meramente por formalidades legais (BOTLER, 2015). Ou seja, é preciso estabelecer a democracia participativa, não em meros eventos e ou instrumentos burocráticos, mas em fatos.

Pois para Padilha, 2004 (apud MAIA, 2013),

A construção de um trabalho educativo de formação política dos educadores docentes e não docentes e dos educandos exige uma prática dialógica entre todos os sujeitos da comunidade escolar, no sentido de superar as relações autoritárias, hierárquicas e verticalizadas. $\mathrm{Na}$ prática dialogada, todos os sujeitos do processo escolar podem falar e serem ouvidos de fato (57).

Há que se considerar também que a lógica neoliberal globalizada e homogeneizadora acaba individualizando as soluções ou, dito de outra forma, as questões coletivas são colocadas em segundo plano, comprometendo o debate a a execução democrática das gestões. Nas escolas onde a proposta é de articulações coletivas, participativas e democráticas, esta concepção, do pensar uma gestão coletivamente, acaba desarticulada e fragmentada, "Perde-se a percepção da totalidade dos processos, ressaltando o individual sobre o coletivo" (Ibidem). 
No Plano Nacional de Educação (PNE) (BRASIL, 2014), a gestão democrática aparece como prioridade, tendo como objetivo estimular o engajamento da comunidade escolar nos destinos da escola. Desse modo, deveria emergir a consciência de que uma gestão escolar fundamentada nas premissas democráticas previstas no PNE, mas dever-se-ia ir além, rompendo com um conformismo de práticas autoritárias e apontando-se para novas possibilidades de participação.

A luta por mais democracia, fonte inesgotável de aperfeiçoamento da convivência humana, tem na educação sua maior sustentação e por isto tem de ser valorizada como prática política e pedagógica em todas as escolas (LUCE; MEDEIROS, 2006, p.25)

Conforme Paro (2000), esta nova escola, neste novo mundo que se almeja não comporta apenas o objetivo de desenvolver atividades de ensino e aprendizagem, mas

\begin{abstract}
Deve permear todas as atividades da escola e é de particular importância na atividade administrativa. Obviamente, uma gestão de escola estruturada em bases democráticas, fundada na participação da comunidade, terá maiores facilidades de conseguir a adesão de parcelas significativas dos pais de alunos, para atividade culturais que visem à reflexão mais profunda dos problemas educacionais de seus filhos, e que lhe propiciem, ao mesmo tempo, a apreensão de uma concepção de mundo mais elaborada e crítica (p. 235).
\end{abstract}

Não podemos deixar de salientar que a democratização da educação passa, necessariamente, pela democratização do acesso e a universalização do ensino para toda a população, sem se deixar de almejar uma qualidade social dessa educação universalizada. Não se devem admitir escolas em que a democracia e a qualidade não sejam a principal premissa educacional. Estas são questões de fundo, que muitas vezes originaram a luta pela universalização da gestão democrática, enquanto elementos decorrentes ou associados à descentralização do poder deliberativo na gestão educacional (LUCE; MEDEIROS, 2006).

A participação e a descentralização passaram a estar presentes em praticamente todos os discursos da reforma educacional, constituindo-se em um novo senso comum, de Projetos Políticos Pedagógicos, por exemplo. O aspecto positivo dessa concepção demonstra o reconhecimento da implicação da educação na democratização e na regulação da sociedade mais ampla.

O desenvolvimento das nações só será efetivo se acontecer através da educação, o que requer a atenção ao o planejamento das condições de ensino e da organização do currículo escolar. A diversidade do cenário social na escola e a ausência do Estado que, sob alegação de estar sobrecarregado (BARROSO, 2005), 
abstêm-se de suas responsabilidades, enquanto transfere poderes e funções para as empresas privadas. Este Estado faz da descentralização e da desburocratização dos processos administrativos, propostas da onda neoliberal atual, desqualificando a educação, simpatizando com a retomada do autoritarismo nas decisões. Por outro lado, diversas pesquisas demonstram que os processos educativos devem primar sempre pela democracia em todos os níveis.

Muitas vezes, em uma abordagem superficial, as diversas proposições de gestão democrática, ou mesmo de descentralização da gestão, podem parecer idênticas ou muito similares. Mas devemos ter o cuidado de examinar a fundo cada proposta de gestão democrática da ou na educação, pois sob as aparências há diferenças e antagonismos matizados por interesses e concepções políticas locais e ou até particulares. A prática da gestão democrática da escola enquanto valor universal é prática de colaboração recíproca e se constitui em um desafio comprometido em garantir que a escola como um todo se efetive em local de diálogo, participação, comprometimento e respeito aos diferentes, saberes, ideologias, posicionamentos, etc. Para Andrade (2015), a escola é ainda o "local de resgate da humanização roubada" (p. 65).

Rocha e Valentini (2015), ao analisarem a gestão das escolas do campo da cidade de São Gabriel-RS, concluem que uma escola democrática que tenha uma gestão participativa, autônoma é ainda uma luta, um ideal a ser alcançado. Porém, o que se vivencia são, muitas vezes, a centralização e o autoritarismo alheios a qualquer tipo de perspectiva democrática (ROCHA E VALENTINI, 2015). Nem por isso, para esses autores, a escola deve deixar de ser o palco em que os conflitos, os debates, as ideologias e as ideias contraditórias, se constituem, em muitas questões, o próprio processo da busca pela gestão democrática e os gestores não devem temer a riqueza desse processo. Um primeiro passo, para fazer da gestão um caminho para ofertar aos educandos a educação que os liberta, objetivo, se não único, o principal de toda escola.

\section{METODOLOGIA DA INVESTIGAÇÃO}

A realização desta pesquisa utilizou-se da abordagem qualitativa do tipo descritiva e documental. Para coleta de dados, foram utilizados, primeiramente, referenciais teóricos norteadores dos aspectos que envolvem a gestão e a democracia, na perspectiva de considerar que a gestão escolar deve ser encarada como um processo de construção democrática, aliada à perspectiva de oferecer aos educandos uma educação de qualidade, que os liberte e seja capaz de promover uma transformação social para uma vida em que a humanidade dos humanos volte a ser a tônica de toda a civilização. 
Após, a metodologia da análise de conteúdo estabelecida por Minayo (2001) fundamenta o tratamento e a interpretação dos dados coletados como etapa importantíssima da pesquisa, pois nela o pesquisador se propõe fazer inferências e interpretações que tentam desvendar o conteúdo subjacente que se manifesta na interpretação de documentos. Considerando esse aspecto e partindo do princípio segundo o qual a análise de conteúdo exige inferência do pesquisador, a neutralidade pode ser considerada uma limitação.

De outra forma, não se deve esquecer que o objeto de análise se constitui também em uma construção simbólica com significado para o pesquisador, e isto deve reverter-se na possibilidade da validação da pesquisa, aspectos que muitas vezes são desconsiderados em abordagens positivistas. Para Thompson "Não se deve considerar que o pesquisador não realize nenhuma inferência, fazendo uso da flexibilidade necessária, e, sim, que tome cuidado, tanto em detalhar como em cumprir as etapas que constituem o método, evitando tanto o positivismo como o idealismo" (MOZZATO; GRZYBOVSKI, 2011, p. 734).

Triviños (1987) considera que o pesquisador que busca encontrar os significados intrínsecos e, por vezes, subjacentes ao objeto pesquisado, deve esforçar-se para ir além do "conteúdo manifesto" dos documentos. As análises qualitativas deverão desvendar o conteúdo latente que eles possuem. Os investigadores que só ficam no conteúdo manifesto dos documentos seguramente pertencem à linha positivista e pouco avançam para a compreensão, quase sempre complexa, de uma realidade social.

Para Minayo (2001), a análise de conteúdo se constitui na análise de informações sobre o comportamento humano, possibilitando uma aplicação em áreas do conhecimento bastante variadas, com funções que vão da verificação de hipóteses e/ou questões e descoberta do que está por trás dos conteúdos manifestos. Tais funções podem ser complementares, com aplicação tanto em pesquisas qualitativas como quantitativas.

Na perspectiva clássica de Bardin (1979), análise de conteúdo foi usada neste estudo para descrever e interpretar o conteúdo de documentos e textos. Essa analise ajudou a reinterpretar as mensagens e a atingir uma compreensão de seus significados num nível que vai além de uma leitura comum. Conforme Bardin,

A primeira atividade consiste em estabelecer contato com os documentos a analisar e em conhecer o texto, deixando-se invadir pelas interpretações. Consequentemente selecionamos os documentos, regimentos, leis que regulamentam o conselho, construindo parte do corpus analisado e as unidades de contexto para descrevê-las, interpretá-las e analisá-las (1979, p. 96), 
Para a análise da gestão escolar da escola, objeto deste estudo, e com o consentimento da atual direção, fez-se uma exploração dos arquivos documentais dos órgãos de gestão da escola; foram analisados os documentos dos seguintes órgãos: Conselho Escolar, Grêmio Estudantil, Círculo de Pais e Mestres- (COM) e Serviço de Supervisão Escolar.

Em síntese, fez-se uma exploração do material documental da escola e escolheram-se os considerados mais relevantes para a pesquisa; nesse sentido, deu-se um tratamento qualitativo aos dados coletados, que serviram para subsidiar os resultados obtidos.

\section{RESULTADOS E DISCUSSÕES}

A pesquisa na escola estadual objeto deste estudo, indica resultados que contribuem para ampliar o debate sobre a democracia nas escolas públicas. A escola analisada, a princípio, busca ser democrática, orientando-se a partir da legislação e das questões teóricas imbricadas. Para aprofundar este debate, apresentamos os resultados da pesquisa.

\section{DIAGNÓSTICO DA ESCOLA E A GESTÃO DEMOCRÁTICA}

A Escola pesquisada foi fundada pela administração municipal do município de São Gabriel no ano de 1937 com a intenção de suprir a necessidade da comunidade gabrielense de uma escola que recebesse os alunos de uma região da cidade em que ainda não havia estabelecimento de ensino. Seus moradores pertenciam a uma classe social de trabalhadores rurais e urbanos em se mantinha longe das escolas, localizadas em regiões mais centrais da cidade. Nos primeiros anos, foram ofertadas apenas as séries iniciais do atual ensino básico.

Vinte anos depois, em fevereiro de 1958, essa passou a ser uma escola administrada pelo Estado do Rio Grande do Sul e passou a oferecer o ensino fundamental completo. Em 2017, a escola oferece os Ensinos Fundamental e Médio, nos três turnos, e atende anualmente uma média de 700 alunos. O corpo docente é composto hoje por 65 professores e possui mais 12 funcionários que trabalham na secretaria, biblioteca, cozinha, limpeza e segurança. As famílias dos alunos possuem renda familiar em torno de três salários mínimos e diversos estudantes entram no mercado de trabalho, geralmente em serviços mal remunerados e com poucas perspectivas de evoluírem profissionalmente, antes de concluírem a Educação Básica. Estes dados são detalhados nos documentos apresentados aos órgãos analisados para esta pesquisa. 
Pelos dados do Índice de Desenvolvimento da Educação Básica (IDEB), a escola pesquisada apresentou sensível melhoria no que diz respeito aos anos iniciais do Ensino Fundamental, passando de 4,4 para 4,6 na última avaliação divulgada no Censo Escolar de 2014. Vale mencionar que, embora o desempenho da Escola tenha melhorado, ficou ainda abaixo da média nacional $(4,9)$, da estadual $(5,4)$ e do próprio município $(4,8)$.

Já nas séries finais do Ensino Fundamental, a escola apresentava média de 3,0 no ano de 2011 e passou a 2,6, na última avaliação. em 2013, ficando muito aquém da média nacional $(4,0)$, estadual $(4,0)$ e do município $(2,9)$.

Segundo dados do Censo Escolar 2014, a escola pesquisada tinha cinco turmas com matrícula superior aos parâmetros sugeridos pelo Conselho Nacional de Educação (CNE), para os Anos Finais do Ensino Fundamental - $5^{\mathrm{a}}$ a $8^{\mathrm{a}}$ série/ $6^{\circ}$ ao $9^{\circ}$ ano e 8 turmas com matrícula superior aos parâmetros sugeridos pelo CNE, para o Ensino Médio.

Outros dados a se salientar referem-se às Taxas de Rendimento (aprovação e reprovação) e ao Movimento escolar (abandono) dos alunos do Ensino Fundamental e Médio. Nesse aspecto, a escola apresenta índices oscilantes para o Ensino Fundamental quando se verifica que, em 2012, a taxa de aprovação foi de $74,2 \%$; em 2013 , de $70,7 \%$ e, em 2014 , de 76,5\%. As taxas de reprovação nesse mesmo período foram, respectivamente, $15 \%, 23,1 \%$ e $10,9 \%$.

O destaque preocupante fica com a taxa de abandono que aumentou para mais de 100\% no período analisado, passando de 6,2\% em 2013 para 12,6\%, em 2014. Especialmente em relação ao Ensino Médio, as taxas divulgadas pelo Censo Escolar em 2014 preocupam, pois a aprovação registrada passa de 67,8\%, em 2012, para 63,1\%, em 2013, e para 58,8\% em 2014. A reprovação registrada foi de 12,1\%, em 2012; 16,9\%, em 2013 e em 18,9\%, em 2014. Já o movimento dos alunos no que se refere ao abandono é $20,1 \%$ em 2012 e diminui para $20 \%$ em 2013, mas volta a crescer em 2014, quando se registram 22,3\% dos alunos matriculados no referido ano.

Em relação à Prova Brasil, verificou-se que nos anos iniciais do Ensino Fundamental $\left(1^{\circ}\right.$ ao $5^{\circ}$ ano), a escola ficou acima da média nacional, tanto em Língua Portuguesa quanto em Matemática. Em Língua Portuguesa, a média nacional foi 189,71 e a da escola foi 190,39, no ano de 2013; uma melhora em relação ao ano de 2011, em que a média nacional era de 185,69 e a da escola de 173,49. Em Matemática, em 2013, a média nacional foi 205,08 e a da escola 205,83, demonstrando também uma sensível melhora em relação ao ano de 2011, quando a média nacional foi 204,58 e a escola apresentou média 190,16. Já nos anos finais do Ensino Fundamental ( $6^{\circ}$ ao $9^{\circ}$ ano), os dados são preocupantes, pois a escola apresentou, em Língua Portuguesa, média de 221,80 e, em Matemática, 229,91, 
índices muito abaixo da média nacional em 2013, 239,39 em Língua Portuguesa e 243,79 em Matemática. Além disso, variou, negativamente, considerando os próprios dados no período entre 2011 e 2013 quando se verifica para Língua Portuguesa 244,86 e Matemática 245,62.

\section{ANÁLISE DOCUMENTAL E A GESTÃO DEMOCRÁTICA}

Com base no estudo dos documentos do conselho escolar, do grêmio estudantil, do círculo de pais e mestres e da supervisão escolar, fez-se uma análise e uma síntese dos resultados encontrados.

O Conselho Escolar reuniu-se oito vezes durante o período de março de 2014 a outubro de 2016, com a participação média de 50\% de seus membros. $\mathrm{Na}$ maioria das reuniões, os segmentos que participaram foram o dos professores e o dos funcionários. Nas oito reuniões registradas houve comparecimento do segmento de pais e alunos em apenas cinco reuniões, não havendo qualquer registro explícito de sua participação.

Os temas registrados nas atas desse conselho se referem basicamente a gestão financeira da escola e, quase sempre, com o intuito único de fiscalização da prestação de contas da direção. Não há registro de questões relacionadas a aspectos educacionais e/ou de gestão do educandário.

Os registros encontrados sobre o grêmio estudantil são parcos e difusos, sem cronologia e sem as atas registradas. Os documentos encontrados indicam que não há este órgão constituído na escola por mais de dez anos.

As reuniões pedagógicas propostas pelo Serviço de Supervisão Escolar mostram que este se constitui em um dos fóruns com registros mais sistematizados. $\mathrm{Na}$ análise de conteúdo realizada a partir das atas disponíveis no período investigado (2012 a 2016), constatou-se uma participação mais efetiva do grupo de docentes da escola, com a participação média de $80 \%$ dos professores. Nesses encontros, os temas discutidos variavam entre planejamento pedagógico, dificuldades de ensino e aprendizagem, problemas de disciplina de alunos, avaliação escolar, participação da família no processo de ensino e aprendizagem.

Percebem-se ainda, no Livro de Atas, registros de encontros de professores para tratar de assuntos referentes, especificamente, às áreas do conhecimento, mas sempre com o foco no planejamento das atividades e/ou com o intuito de avaliar a prática pedagógica.

Também constam desses registros relatos de atas de conselhos de classe das turmas do Ensino Fundamental e Médio da escola. Esses encontros são, exclusivamente, entre o Setor de Supervisão e a turma de alunos, que 
conversam sobre conflitos e anseios da turma, que, pelos registros, são levados em reuniões posteriores, ao conhecimento dos professores da turma para análise e encaminhamentos.

Os registros da reunião do Circulo de Pais e Mestres são difusos e sem atas registradas durante o período analisado. Supõe-se, pelos documentos apresentados, que não houve reuniões desse fórum de gestão. Apenas há registros da ata da posse dos seus membros.

Notam-se, pelos registros encontrados nos órgãos de gestão da escola, que o processo de gestão escolar ainda está carente de participação democrática mais efetiva. Os principais fóruns de gestão destacados como democráticos parecem apenas cumprir requisitos básicos da exigência legal.

Após análise dos documentos relacionados a fóruns de gestão da escola em questão, verificou-se que em muitos destes fóruns não existe participação efetiva dos seus membros.

Há, pelos registros, pouquíssima participação dos pais e da comunidade escolar nas decisões de gestão.

\section{CONSIDERAÇÕES FINAIS}

A Gestão Democrática em uma escola pública é um dos fatores considerados essenciais para a melhora do desempenho do ensino e da aprendizagem. Já na LDB (BRASIL, 2005), após mais de uma década de vivência da democracia no Brasil, a participação passou a ser condição obrigatória na construção dos projetos Políticos Pedagógicos de todas as escolas brasileiras.

Nesse contexto, a partir dos dados de pesquisa analisados, percebe-se que a escola pesquisada possui índices aquém do requerido pelos documentos oficiais e estudos sobre a temática. Alguns fatores necessitam ser considerados para a explicação desses baixos índices de participação, como o grau de participação da comunidade escolar na gestão da escola, destacado nesta análise. Este se mostrou ainda em construção, pois o Conselho Escolar realiza poucas reuniões e com baixo índice participativo de seus membros. Já o Serviço de Supervisão Escolar aparece como órgão consultivo da escola com considerável participação de professores e alunos.

A análise traz como preocupação a inexistência de um Grêmio Estudantil ativo, pois, segundo informações da atual direção, apenas no $2^{\circ}$ semestre de 2016 ele recomeçou suas atividades, após dez anos sem qualquer registro de manifestação deste órgão. 
Quanto ao Círculo de Pais e Mestres não há registro para uma análise de sua efetividade, e segundo informações da atual direção não houve reuniões desse órgão após a posse dos atuais membros (dois anos).

Esta pesquisa ateve-se especialmente à análise qualitativa dos órgãos de gestão da escola, trazendo para essa análise dados quantitativos da escola. Para um melhor diagnóstico seria importante analisar dados sociais e econômicos das famílias dos estudantes, bem como os de contextos pedagógicos de pesquisas com o corpo docente, temas para futuras investigações.

Fica o desafio para os investigadores e educadores que se atêm ao tema da democracia em escolas públicas, mas, e especialmente, os resultados desta investigação procuram contribuir com os gestores dessa escola, para que se efetive a participação na gestão escolar dos órgãos representativos. Registra-se que o acesso aos documentos para esta pesquisa é um passo importante que a atual direção dá para tornar a escola uma referência na construção democrática de uma gestão efetivamente representativa.

\section{REFERÊNCIAS}

ANDRADE, R. M. M. Um desafio na construção e efetivação de espaços dialógicos e participativos na escola. In: MARTINS, Claude da Silva Lima et.all (Org.) Fortalecendo a Educação e suas relações nos espaços educacionais. Vol.1. Bagé - RS: Fundação Universidade Federal do Pampa, 2015.

AZANHA, J. M. P. Uma reflexão sobre a formação do professor da escola básica. Educação e Pesquisa, São Paulo, v.30, n.2, p. 369-378, maio/ago. 2004

BARDIN, L. Análise de Conteúdo. Lisboa: Ed. 70, 1979.

BARroso, J. O Estado, a Educação e a regulação das Políticas Públicas. Educação e Sociedade. Campinas, vol. 26, n. 92, p. 725-751, Especial - Out. 2005

BOTLER, A. M. H. Repercussões das políticas educacionais na organização escolar: o fator tempo entre a autonomia e a regulação. Revista Brasileira de Política e Administração da Educação - RBPAE - v. 31, n. 1, p. 107 - 124, jan./abr. 2015.

BOBBIO, Norberto. A era dos direitos. 9. ed. Rio de Janeiro: Campus, 2004. 
BRASIL. Plano Nacional de Educação (PNE) 2014-20124 (Lei no 13005 de 25 de Junho de 2014). Disponível em: <www.planalto.gov.br/ccivil_03/_ato20112014/2014/lei/113005.htm>. Acesso em: 26 Out. 2016.

BRASIL. LDB. Lei de Diretrizes e Bases da Educação Nacional. MEC/ Brasília, 2005. Disponível em: <https://www2.senado.leg.br/bdsf/bitstream/ handle $/$ id $/ 70320 / 65$.pdf? sequence $=3>$. Acesso em maio de 2017>.

CÓSSIO et al. Gestão educacional e reinvenção da democracia: questões sobre regulação e emancipação. Revista Brasileira de Política e Administração da Educação - RBPAE - v.26, n.2, p.325-341, mai./ago. 2010

CURY, C. R. J. Por um novo plano nacional de educação. In: Cadernos de Pesquisa. v 41, n 144, set/dez 2011, p.790-811.

CURY, C. R. J. Gestão democrática da educação: exigências e desafios. In: Revista Brasileira de Política e Administração da Educação. São Bernardo do Campo, v. 18 , n.2, jul/dez 2002, p.163 -174.

DOURADO, L. F. A escolha de dirigentes escolares: políticas de gestão da educação no Brasil. In: FERREIRA, Naura S. Capareto (Org). Gestão Democrática da Educação: atuais tendências, novos desafios. 3 ed. São Paulo: Cortez, 1998.

FLACH, S. F.; SAKATA, K. L.S. O princípio da gestão democrática na educação pública e sua efetivação no âmbito do sistema municipal de ensino de Ponta Grossa- PR. Revista Brasileira de Politica e Administração da Educação RBPAE - v. 32, n. 2, p. 549 - 569 mai./ago. 2016.

LUCE, M. B; MEDEIROS, I. L. P. Gestão Escolar Democrática: concepções e vivências. Porto Alegre: UFRGS, 2006.

MAIA, B. P. Os desafios e as superações na construção coletiva do Projeto Político Pedagógico. Curitiba: Intersaberes, 2013 - (Séries Processos Educacionais).

MINAYO, M. C. S. (Org.). Pesquisa Social: Teoria Método e Criatividade. $17^{a}$ ed. Petrópolis, RJ: Vozes, 2001. 
MOZZATO, A. R.; GRZYBOVSKI, D. Análise de Conteúdo como Técnica de Análise de Dados Qualitativos no Campo da Administração: Potencial e Desafios. ANPAD/RAC, 2011. Disponível em http:/ /www.anpad.org.br/rac

PARO, V. H. Estrutura da Escola e prática Educacional Democrática - USP - GT: Estado e Política Educacional/n.5. Agência Financiadora: CNPq, 2010. Disponível em: <http://30reuniao.anped.org.br/trabalhos/GT05-2780--Int. pdf $>$. Acesso mai. 2017.

PARO, V. H. Gestão Democrática da Escola Pública. 5. ed. São Paulo: Ed. Xamã, 2000.

PENIN, S.; VIEIRA, S. Refletindo sobre a função social da Escola. In: VIEIRA, S. L. (Org.). Gestão da escola: desafios a enfrentar. Rio de Janeiro: DP\&A, 2002. p. 13- 45.

ROCHA, J. M.; VALENTINI, L. M. A. B. Escola do Campo: desafios para o enraizamento de uma prática educacional democrática. Jundiaí: Paco Editorial: 2015.

SARTORI, J. Formação do professor em serviço: da (re) construção teórica e ressignificação da prática. Passo Fundo: Ed. Universidade de Passo Fundo, 2013.

TRIVIÑOS, A. Introdução à pesquisa em ciências sociais: a pesquisa qualitativa em educação. São Paulo: Atlas, 1987.

VALENTINI, L. M. A. B.; ROCHA, J. M. Cortando a Cerca: Uma Escola do Campo frente à Multiculturalidade Contemporânea. Revista Monografias Ambientais, v. 8, p. 1798-1816, 2012.

JEFFERSON MARÇAL DA ROCHA possui graduação em Ciências Econômicas pela Fundação Educacional de Alegrete (1989), mestrado em Desenvolvimento Regional pela Universidade de Santa Cruz do Sul - Bolsa CNPq (1999), doutorado em Meio Ambiente e Desenvolvimento pela Universidade Federal do Paraná - Bolsa Capes (2004) e Pós-doutorado em Gestão Ambiental (UNEX - Universidade de Extremadura- ESPANHA, 2005/2006 - Bolsa CE) e em 
Desenvolvimento Regional (Universidade de Santa Cruz do Sul - 2017/2018 Bolsa Capes). Atualmente é professor Associado da Universidade Federal do Pampa (UNIPAMPA), docente do Programa de Pós-Graduação em Educação - Mestrado Profissional (PPGEdu) da Unipampa, professor colaborador do PPGA da Universidade de Caxias do Sul. E-mail: jeffersonmrocha@gmail.com

LÚCIO JORGE HAMMES possui graduação em Filosofia pela Faculdade de Filosofia N S da Imaculada Conceição (1988), graduação em Teologia pela Pontifícia Universidade Católica do Rio Grande do Sul (1993), mestrado em Teologia pela Pontifícia Universidade Católica do Rio Grande do Sul (2000) e doutorado em Educação pela Universidade do Vale do Rio dos Sinos (2005). Atualmente é professor associado da Universidade Federal do Pampa. Tem experiência na área de Educação, com ênfase em Filosofia da Educação, atuando principalmente nos seguintes temas: cidadania, capital social, cultura de paz, juventude e desenvolvimento sustentável. E-mail: luciohammes@unipampa.edu. br

Recebido em julho de 2017 Aprovado em novembro de 2017 